Article

\title{
Sustainable Care and Factors Associated with Quality of Life among Older Beneficiaries of Social Services
}

\author{
Mihaela Ghența ${ }^{1, *} \mathbb{C}$, Aniela Matei ${ }^{1}$, Luise Mladen-Macovei ${ }^{1}$, Maria Denisa Vasilescu ${ }^{1,2}$ \\ and Elen-Silvana Bobârnat ${ }^{1} \mathbb{B}$ \\ 1 National Scientific Research Institute for Labour and Social Protection (INCSMPS), \\ 010643 Bucharest, Romania; aalexandrescu@incsmps.ro (A.M.); luisemladen@hotmail.com (L.M.-M.); \\ mariadenisa.vasilescu@gmail.com (M.D.V.); silvana.bobarnat@incsmps.ro (E.-S.B.) \\ 2 The Faculty of Economic Cybernetics, Statistics and Informatics, The Bucharest University of \\ Economic Studies, 010552 Bucharest, Romania \\ * Correspondence: ghenta@incsmps.ro
}

Citation: Ghența, M.; Matei, A.; Mladen-Macovei, L.; Vasilescu, M.D.; Bobârnat, E.-S. Sustainable Care and Factors Associated with Quality of Life among Older Beneficiaries of Social Services. Sustainability 2021, 13 , 1572. https://doi.org/10.3390/ su13031572

Academic Editors: Nuno Crespo and João Leitão

Received: 1 December 2020

Accepted: 27 January 2021

Published: 2 February 2021

Publisher's Note: MDPI stays neutral with regard to jurisdictional claims in published maps and institutional affiliations.

Copyright: (c) 2021 by the authors. Licensee MDPI, Basel, Switzerland. This article is an open access article distributed under the terms and conditions of the Creative Commons Attribution (CC BY) license (https:// creativecommons.org/licenses/by/ $4.0 /)$.

\begin{abstract}
Population aging has led to an increased recognition of the problems encountered by older persons. As a consequence, the most recent years have been marked by a series of changes with regard to the organization and provision of social services for dependent older people. The aim of this article is to identify factors associated with the quality of life in old age, using a logistic regression applied to the data collected following a field survey among the beneficiaries of social services. The analysis revealed that men are more likely to appreciate that life does not make sense, compared to dependent elderly women. Age is also a significant factor that influences the quality of life: the older the people are, the more they tend to think in a positive manner about their life. Health, social participation and food are also important factors that influence the perception regarding the quality of life.
\end{abstract}

Keywords: sustainable care system; social services; quality of life; older people

\section{Introduction}

As a result of economic and technological developments, life expectancy is continuously improving and the European elderly population is becoming more numerous. These demographic changes have long-term effects on social protection systems and society as a whole; they require specific interventions as the needs and expectations of these people are different from those of other categories of population. First, the ability of older people to live autonomously is often affected by the prevalence of diseases associated with old age, and this leads to an increase in the need for social and socio-medical services [1]. Secondly, the families of these people need access to various social services in order to face the difficulties related to the care of a dependent older person.

All these transformations were reflected in the development of research concerning the effects of the ageing population at different levels: the micro level-individual; the meso level—organizations that provide social and socio-medical services; the macro level—public policy makers.

Sustainable ageing, in general, and sustainable care, in particular, have three broad components: an economic component, an environmental one and a social pillar [2,3].

Economic sustainability of ageing and care points to the increasing costs of social care for the elderly. An ageing population is pushing up the cost of caring for older and disabled people, placing the social care systems under huge pressure. A sustainable health and care system can help older people live a dignified life and at the same time can reduce the burden of care for their families [4].

At the EU level, in 2010, the expenditures on long-term care were $1.8 \mathrm{pp}$ on countries' GDP and by 2060 are estimated to be more than 3.5 pp [5]. Regarding Ro- 
mania, the same authors [5] estimate that by 2060 the public expenditure on long-term care will have increased up to almost 2 pp on GDP. Moreover, the Romanian social services system dedicated to the older persons have changed during the last few years, as a consequence of the European's attention to ageing phenomenon and its social and economic consequences. Most of the changes have been driven by the necessity to ensure a long-term sustainability of the social assistance system, as the demographic changes pressure the social protection system and require solutions balanced in terms of expectations of older persons and public budget possibilities.

Sustainable environment for elderly people means, among others, adapting buildings and residential buildings in particular, for elderly needs: obstacle-free and easy access buildings, both indoors and outdoors, for residents at different stages of their lives, adjustable spaces and inclusive design, with the use of ICT technologies and solutions [6].

Regarding the social aspects, a sustainable care system takes into account not only the distribution of resources, but also the people's individual needs satisfaction, well-being, and quality of life [7].

This article mainly focuses on the perceptions of elderly people related to factors associated with the quality of life (QoL) and provides information that can be used to design a sustainable care system that includes the perceptions of older beneficiaries. The aim of this article is to identify factors associated with the quality of life in old age, using a logistic regression applied to the data collected following a field survey among the beneficiaries of social services. Our core research questions in the context of the national care system dedicated to older persons were: (i) to assess if the quality of life among the elderly is influenced by their health status; (ii) to test if the social ties (partner, family, and friends) have a positive impact on the perceived quality of life; (iii) to draw a conclusion on how the social services for the elderly actually contribute to their quality of life. The first part of the article presents a short description of the social services architecture within the Romanian social assistance system, followed by a literature review section concerning quality of life in general and quality of life in old age in particular. The third section covers the method selected and applied to identify the factors associated with the quality of life and the last part of the article presents and discusses the results. This research contributes to the general understanding of determinants of QoL in old age based on the perception of older dependent persons.

\section{Social Care Policy Addressing Older People}

Social and socio-medical services have evolved a lot in recent years, both in number and structure, in trying to adapt to the growing needs generated by the continuous phenomenon of population aging. Today in Romania live 3,751,731 people aged 65 and over [8], representing $16.9 \%$ of the country's population, with $2.3 \mathrm{pp}$. more than ten years ago.

The accentuation of the aging population and the increase in life expectancy determined the appearance of the fourth age or the oldest-old-people aged 80 and over. The share of this category in the total elderly population increased from $21.2 \%$ in 2010 to $25.0 \%$ in 2020 .

The aging index, calculated as the number of 65-year-old people and over, per 100 children under 15 years, increased by $21.4 \%$ between 1 st of January 2010 and 1st of January 2020, from 95.2 to 115.6. Thus, nowadays the number of older persons exceeds the number of children. This development will probably have implications over the way society's resources will be distributed amongst generations [9].

The changes in the demographic structure have a strong impact both economically and socially. Increasing longevity entails higher costs for health care, long-term care and social protection for older people, threatening the sustainability of the system.

Aging is associated with a constant deterioration in health, fragility, low potential of activity and the risk of dependency. The state of dependence of the older population is determined by the presence of degenerative diseases that reduce the mobility of the 
individual, by the progressive decrease in memory and sometimes by the appearance of symptoms of senile dementia, by the strong restriction of social and professional roles.

One of the major problems faced by the older people in Romania is the economic dependency [10] determined by the low level of material resources available for this vulnerable group of population.

In Romania, the older people have the right to social assistance in relation to the sociomedical situation and the economic resources. Social assistance for the elderly is provided through social services and social benefits. The aim of the social assistance intervention is to support those in difficulty to obtain the conditions necessary for a decent life, helping them to develop their own abilities and skills. Social services are structural components of the social assistance system, contributing to the social inclusion of beneficiaries, helping them to overcome difficult situations and increasing their quality of life.

The main types of social services addressed to the elderly provided by both public and private social service providers (associations, foundations, cults recognized by law) are the following:

- Temporary or permanent home care;

- Temporary or permanent care in a home for the elderly;

- Care in day centers, clubs for the elderly, temporary care homes, apartments and social housing, and the like.

Temporary or permanent home care consists of providing:

- Social services-personal care, prevention of social marginalization and support for social reintegration, legal and administrative advice, support for the payment of current services and obligations, care of housing and household, help with housekeeping and food preparation;

- Socio-medical services-basic activities of daily living, mainly: ensuring body hygiene, help with dressing and undressing, rehabilitation of physical and mental abilities, adapting the home to the needs of the elderly, moving indoors and communicating, and temporary care in day centers, night shelters or other specialized centers;

- Medical services-consisting of providing consultations and medical care at home or in health institutions, dental consultations and care, administration of medicines, provision of sanitary materials and medical devices.

Temporary or permanent care in a home for older persons consists of:

- Social services-help for housekeeping, legal and administrative counseling, ways to prevent marginalization and social reintegration in relation to psycho-affective capacity;

- Socio-medical services-help for maintaining or rehabilitating physical or intellectual abilities, ensuring occupational therapy programs, support for achieving body hygiene; - Medical services-consultations and treatments at the medical office, in specialized medical institutions or at the person's bed, if he is immobilized, care-infirmary services, insurance of medicines, provision of medical devices, consultations and dental care.

However, home care and keeping the elderly in their living environment are much more suitable for those in difficulty, with emotional benefits for them.

The access of an older person to the residential center is allowed only if they require special permanent medical care, which cannot be provided at home; he cannot manage on his own; is without legal supporters or they are unable to fulfill their obligations due to their health or economic situation and family responsibilities; he has no home and no income of his own.

Among the main causes of the long-term institutionalization of the older people, were identified [11]: loneliness and lack of support network; the manifest desire of the elderly; lack of income; various chronic conditions; physical or mental disability; home loss; maladaptation to home care services; misunderstandings within the family; bed immobilization; abuse of caregivers/relatives.

In order to respond as adequately as possible to the social needs of the elderly and the particular conditions in which they find themselves, social services are organized with 
priority at the level of local communities [12]. Local public administration authorities are responsible for identifying and assessing the needs of older people, organizing, planning and ensuring the financing or co-financing of social services, and public and private social service providers are responsible for providing them in compliance with quality standards.

On the Romanian social services market, non-governmental organizations are the most important private actors both by their number and by the diversity of social services offered to those in need [12]. Unfortunately, the territorial distribution of non-governmental organizations as private providers of social services is uneven, with areas where their number is very small.

In the field of social services for the elderly, the public-private partnership allows one to increase the quality of life of these individuals or families in a situation of social need. The partnership ensures the prompt provision of these services in the communities that need them most (poor communities, rural communities).

The quality of life of older people is closely linked to the social protection system and the quality of social services they receive.

The social field in general and that of social and socio-medical services in particular must find appropriate solutions to the problems faced by the elderly population and measures that increase the quality of life of these people must be implemented.

\section{Literature Review}

Central to this research is the concept quality of life, a concept that includes two broad perspectives-an objective perspective and a subjective one [13], with some indicators taking into account both of the two aspects.

From an objective perspective, the concept quality of life (QoL) encompasses aspects such as life conditions, living conditions, nutrition, environment, income level, etc., aspects that are usually evaluated through the use of tools developed by experts $[13,14]$. Although these aspects are significant in terms of social policy regulations, research into quality of life should also consider the subjective perspective of individuals [15].

From a subjective perspective, quality of life captures how the individual perceives his own life and it concerns the individual's happiness, well-being, and quality of experience. The standards of reference are individual's expectations, values, personality traits and experiences and are influenced by factors such as socio-economic level, intellectual activity, cultural values, lifestyle, daily satisfaction and living environment [16]. Due to the importance of beneficiary's centrality in designing social services, different authors [17-19] argue that subjective measurement of the quality of life should take precedence.

Both of the two perspectives encounter criticism. The main criticism of the objective perspective is that alone it captures general aspects of life, such as illness and treatment, but does not offer insights on the individual's perceptions and preferences $[15,20]$. Regarding the subjective evaluation, alone it may lead to incomplete or erroneous conclusions [17], especially when used in a particular social policy context [21]. Second, when studying the quality of life of elderly people suffering from cognitive impairment, trustworthy subjective measurements are also difficult to obtain.

Eurostat uses both subjective and objective aspects for measuring the quality of life. The indicator Quality of Life encompasses nine dimensions, eight of them concerning the functional capacities that citizens should have access to-material living conditions, productive or main activity, health, education, leisure, economic security and physical security, governance and basic rights, the natural and living environment, and the ninth dimension of the concept capturing to life satisfaction and well-being-the general experience of life [22].

Human needs may also ground the theory and evaluation of quality of life, based on A.H. Maslow's theory of human motivation [17]. At the bottom of the hierarchy are the physiological needs, and the safety and security needs, followed by love, affection and belongingness needs, subsequent are self-respect and self-confidence and the respect of 
others, and lastly is the need of self-actualization. Only when the needs from one level are fulfilled, the individual can endeavor to satisfy the needs on the next level.

According to WHO [23], quality of life is "an individual's perception of their position in life in the context of the culture and value systems in which they live and in relation to their goals, expectations, standards and concerns" and it is influenced by different factors, such as physical health, psychological state, level of independence, social relationships, personal beliefs and the environment in which the person lives. The WHO definition incorporates health-related aspects, psychological aspects, cultural and social aspects. This definition of quality of life developed by WHO is most often referred to when examining the quality of life.

The social phenomena of growing life expectancy stimulated the research regarding the quality of life of the elderly [24]. Approached for the first time in medical research, quality of life further expanded into sociology, psychology and social work. The aim of identifying the general characteristics of a good life, including good life in old age, conducted elaborated literature regarding the subject.

The quality of life is a multidimensional, multifactorial construction [13,21,25], and contrary to various stereotypes, the definition of a good quality of life in old age is often similar to that identified for other age groups [26]. However, given that older people are usually affected by physical and mental pathologies, many of them require long-term care [27], physical and mental health, as well as functional capacity, gain a much stronger emphasis when measuring their quality of life [28]. Health is a resource that allows elderly people to fulfill social activities and to engage in activities of daily living [29]. The ability to accomplish these activities vastly influences the way these people perceive their quality of life.

As the elderly form a heterogeneous group, and considering the impact of physical and mental health on the quality of life of individuals, research conducted in recent decades emphasized the importance of medicine in gerontology [21] and led to the Health-Related Quality of Life (HRQoL) approach [14]. In addition, a person's previous experiences, emotional state, personality, and expectations make the measuring and evaluating of quality of life a difficult process [27].

Through a systematic review concerning the quality of life of the elderly in general, research conducted in five countries of the European Union-Germany, Italy, the Netherlands, Sweden and UK - eight key factors of the quality of life of older people were identified: environments, including housing, quality of the neighborhood, quiet surroundings, good environmental conditions and transport, physical and mental health, employment and retirement, income and wealth, family and support networks, including both qualitative and quantitative aspects, such as intergenerational family solidarity, neighbors and friends emotional support, the frequency of social contacts, etc., participation in organizations and associations, access to health and social care services, life satisfaction and wellbeing, which is a subjective dimension of quality of life [30]. The research also identifies structural factors, corresponding to social demographic variables that influence the quality of life of in old age: social class, gender and ethnicity [31,32]. In a systematic review of 48 qualitative studies, the authors of [25] identified nine interconnected QoL domains: health perception, autonomy, role and activity, relationships, attitude and adaptation, emotional comfort, spirituality, home and neighborhood, financial security.

A study on elderly living in Slovakia [33] identified three categories of factors influencing their quality of life: demographic factors, containing age and sex, socio-economic factors, containing marital status, education and income, and health factors containing functional status, anxiety and depression. Quality of life may be also influenced by the characteristics of dwellings [34] or involvement in recreational activities [35].

Regarding people suffering from severe physical and/or mental disabilities, that are residents in institutional care, studies [36] reveal four aspects of quality of life for those people: sense of self, including appearance, personal possessions, privacy, participation to meaningful activities, the environment, with two main aspects, control and autonomy 
and the relationship with the staff and relationships with other residents and relationships with family.

A study on the factors related to the QoL of older people hospitalized and receiving post-acute rehabilitation services in Switzerland [37] revealed that depression is significantly associated with elderly perception of their quality of life.

According to other studies focused on residents' quality of life in long-term care settings, three broad categories of factors that influence the quality of life in old age were identified: core factors, mediating factors and facilitating/constraining factors. Core factors consist of care environment and ethos of care, sense of self and identity, connectedness, social relationship and networks, activities and therapies. Mediating factors consist of personality and life experiences, adaptive responses, health status/dependency level and expectations. Facilitating/constraining factors consist of physical and social environment $[13,15]$.

\section{Data and Methodology}

\subsection{Data Source}

The data source used in this article is a survey database from The Quality of Life for Elderly in Romania project financed through Sectorial Research Plan of the Ministry of Labour and Social Protection from Romania. This specific survey on the quality of life of dependent elderly beneficiaries targeted social services with accommodation (care homes for the elderly-social service code $8730 \mathrm{CR}-\mathrm{V}-\mathrm{I}$, respite centers for the elderly-social service code $8730 \mathrm{CR}-\mathrm{V}$-II, sheltered housing-social service code $8730 \mathrm{CR}-\mathrm{V}-\mathrm{III}$ ) and social services without accommodation (day care and recovery centers-social service code 8810 CZ-V-I and home care units—social service code 8810 ID-I). The codes correspond to the nomenclature of social services in Romania approved by DECISION No. 867/2015 of 14 October 2015 for the approval of the nomenclature of social services, as well as of the framework regulations for organization and functioning of social services.

The main objective of the survey conducted among the elderly was to identify the determinants of the quality of life of dependent elderly people who benefit from social services with and without accommodation.

Based on specialized literature and tools developed internationally [38] a set of indicators were developed and tested in 8 regional focus groups and 6 semi-structured interviews with various categories of people interested in social services for this category of population (beneficiaries, organizations representing the interests the elderly, social service providers). After this methodological step, the questionnaire was recalibrated and pretested. The tool developed and applied in the field survey includes 28 questions developed based on 41 indicators pretested grouped in 7 dimensions, as follows: emotional well-being/wellbeing ( 8 indicators), disposable income and their management ( 3 indicators), functional autonomy (10 indicators), food and nutrition (3 indicators), control, quality of care (8 indicators), social participation and involvement (10 indicators), living environment (housing and community) (4 indicators). A series of socio-demographic identification variables for respondents is found in the questionnaire developed to allow an in-depth analysis of the data.

The survey based on a standardized face-to-face questionnaire was applied using TAPITablet Assisted Personal Interview technique between 7 August 2019 and 23 September 2019. Completing a questionnaire took an average of $20 \mathrm{~min}$. The data were analyzed using IMB SPSS 20 statistical software. The population of beneficiaries of social services for the elderly (social services with and without accommodation) was extracted from the Register of accredited social services' providers of The Romanian Ministry of Labour and Social Protection. The sampling procedure was based on a two-stage stratification method that ensures a representative distribution at national level, in terms of distribution of providers and beneficiaries. The first stage of the stratification method targeted the social service providers, and the second stage targeted the social service beneficiaries. The survey is nationally representative for the social services with a $3.5 \%$ margin of error at $95 \%$ 
confidence level. The representativity for the type of service is, in the case of beneficiaries of social services with accommodation margin of error of $3.086 \%$, at a $95 \%$ confidence level, and in the case of beneficiaries of social services without accommodation margin of error of $3.34 \%$, at a confidence level of $95 \%$.

In total, 655 dependent elderly people were interviewed, comprising 355 dependent elderly people from social services with accommodation, and 300 dependent elderly people from social services without accommodation (Table 1). Only persons aged 65 years and over with a physical dependency were included in this survey. All ethical issues regarding confidentiality, informed consent and anonymity were addressed during the process of data collection.

Table 1. Main characteristics of the sample.

\begin{tabular}{|c|c|c|c|}
\hline Name of the Characteristic & $\begin{array}{c}\text { Total } \\
(\mathrm{n}=655) \\
\mathrm{n} \%\end{array}$ & $\begin{array}{l}\text { Services with } \\
\text { Accommodation } \\
\quad(n=355)\end{array}$ & $\begin{array}{l}\text { Services without } \\
\text { Accommodation } \\
\quad(n=300)\end{array}$ \\
\hline \multicolumn{4}{|l|}{ Sex } \\
\hline Male & $230(35.1 \%)$ & $146(41.1 \%)$ & $84(28 \%)$ \\
\hline Female & $425(64.9 \%)$ & $209(58.9 \%)$ & $216(72 \%)$ \\
\hline \multicolumn{4}{|l|}{ Civil status } \\
\hline Married/Consensual Union & $83(12.7 \%)$ & $18(5.1 \%)$ & $65(21.6 \%)$ \\
\hline Single/Widowed & $572(87.3 \%)$ & $337(94.9 \%)$ & $235(78.3 \%)$ \\
\hline \multicolumn{4}{|l|}{ Residential area } \\
\hline Urban & $433(66.1 \%)$ & $217(61.1 \%)$ & $216(72 \%)$ \\
\hline Rural & $222(33.9 \%)$ & $138(38.9 \%)$ & $84(28 \%)$ \\
\hline \multicolumn{4}{|l|}{ Last education level } \\
\hline Without education & $4(0.6 \%)$ & $2(0.6 \%)$ & $2(0.7 \%)$ \\
\hline ISCED 1-2 & $218(33.3 \%)$ & $81(22.8 \%)$ & $137(45.7 \%)$ \\
\hline ISCED 3-4 & $336(51.3 \%)$ & $202(56.9 \%)$ & $134(44.6 \%)$ \\
\hline ISCED 5-8 & $97(14.8 \%)$ & $70(19.7 \%)$ & $27(9 \%)$ \\
\hline \multicolumn{4}{|l|}{ Age } \\
\hline 65-74 years & $238(36.3 \%)$ & $126(35.5 \%)$ & $112(37.3 \%)$ \\
\hline $75-84$ years & $261(39.8 \%)$ & $138(38.9 \%)$ & $123(41 \%)$ \\
\hline 85 years and over & $156(23.8 \%)$ & $91(25.6 \%)$ & $65(21.7 \%)$ \\
\hline \multicolumn{4}{|l|}{ The period of accessing the service } \\
\hline Under 12 months & $133(20.3 \%)$ & $82(23.1 \%)$ & $51(17 \%)$ \\
\hline 12-24 months & $110(16.8 \%)$ & $68(19.2 \%)$ & $42(14 \%)$ \\
\hline $24-36$ months & $93(14.2 \%)$ & $55(15.5 \%)$ & $38(12.7 \%)$ \\
\hline 36-48 months & $68(10.4 \%)$ & $32(9.0 \%)$ & $36(12 \%)$ \\
\hline 48 months and over & $251(38.3 \%)$ & $118(33.2 \%)$ & $133(44.3 \%)$ \\
\hline \multicolumn{4}{|l|}{$\begin{array}{l}\text { Monthly income of the elderly } \\
\text { (in Euro, } 1 \text { Euro = RON 4.873) }\end{array}$} \\
\hline Average income & 252 & 278 & 221 \\
\hline Q1 (First quartile) & 140 & 154 & 131 \\
\hline Q2 (Second quartile) & 226 & 267 & 182 \\
\hline Q3 (Third quartile) & 328 & 369 & 307 \\
\hline \multicolumn{4}{|l|}{ Ownership of social service } \\
\hline Public & $291(44.4 \%)$ & $205(57.7 \%)$ & $86(28.7 \%)$ \\
\hline Private & $364(55.6 \%)$ & $150(42.3 \%)$ & $214(71.3 \%)$ \\
\hline
\end{tabular}


There are some studies available investigating what quality of life actually means for older people. An interpretative hermeneutic phenomenological analysis conducted by [39] revealed that quality of life in old age means a preserved self and meaning in existence. In another study, quality of life in old age is described as a sense of well-being, meaning and value [40]. The authors of [40] believe that a person who experiences a reasonable degree of well-being is a person who can see some meaning in life. Therefore, we consider that the use of the perception regarding the meaning of life as a proxy for quality of life for older people is appropriate given the purpose of this article (identification of factors associated with the quality of life of elderly beneficiaries from social services). A binary variable measuring subjective perception of the respondents regarding the meaning of life was developed starting from the question "How would you characterize your life right now?". The answer options "other answer" and "I can't appreciate" were considered missing, the final sample used for the analysis in this article thus containing the answers of 640 elderly peoples (Table 2).

Table 2. Distribution of respondents based on their perceived meaning of life.

\begin{tabular}{|c|c|c|c|}
\hline Name of the Characteristic & $\begin{array}{c}\text { Total } \\
(\mathrm{n}=640) \\
n \%\end{array}$ & Life Has a Meaning $(n=372)$ & Life Has No Meaning $(n=268)$ \\
\hline \multicolumn{4}{|l|}{ Sex } \\
\hline Male & $35.5 \%$ & $35.2 \%$ & $35.8 \%$ \\
\hline Female & $64.5 \%$ & $64.8 \%$ & $64.2 \%$ \\
\hline \multicolumn{4}{|l|}{ Civil status } \\
\hline Married/Consensual Union & $12.5 \%$ & $12.9 \%$ & $11.9 \%$ \\
\hline Single/Widowed & $87.5 \%$ & $87.1 \%$ & $88.1 \%$ \\
\hline \multicolumn{4}{|l|}{ Residential area } \\
\hline Urban & $65.8 \%$ & $64.8 \%$ & $67.2 \%$ \\
\hline Rural & $34.2 \%$ & $35.2 \%$ & $38.8 \%$ \\
\hline \multicolumn{4}{|l|}{ Last education level } \\
\hline Without education & $0,6 \%$ & $1.1 \%$ & - \\
\hline ISCED 1-2 & $33.0 \%$ & $31.7 \%$ & $34.7 \%$ \\
\hline ISCED 3-4 & $51.6 \%$ & $53.0 \%$ & $49.6 \%$ \\
\hline ISCED 5-8 & $14.8 \%$ & $14.2 \%$ & $15.7 \%$ \\
\hline \multicolumn{4}{|l|}{ Age } \\
\hline $65-74$ years & $37.0 \%$ & $37.9 \%$ & $35.8 \%$ \\
\hline $75-84$ years & $39.2 \%$ & $35.2 \%$ & $44.8 \%$ \\
\hline 85 years and over & $23.8 \%$ & $26.9 \%$ & $19.4 \%$ \\
\hline \multicolumn{4}{|l|}{ The period of accessing the service } \\
\hline Under 12 months & $20.6 \%$ & $19.9 \%$ & $21.6 \%$ \\
\hline $12-24$ months & $16.4 \%$ & $16.1 \%$ & $16.8 \%$ \\
\hline $24-36$ months & $14.5 \%$ & $14.2 \%$ & $14.9 \%$ \\
\hline 36-48 months & $10.5 \%$ & $9.4 \%$ & $11.9 \%$ \\
\hline 48 months and over & $38.0 \%$ & $40.3 \%$ & $34.7 \%$ \\
\hline \multicolumn{4}{|l|}{$\begin{array}{l}\text { Monthly income of the elderly (in } \\
\text { Euro, } 1 \text { Euro = RON 4.873) }\end{array}$} \\
\hline Average income & 252 & 243 & 266 \\
\hline Q1 (First quartile) & 140 & 133 & 144 \\
\hline Q2 (Second quartile) & 226 & 205 & 246 \\
\hline Q3 (Third quartile) & 328 & 308 & 349 \\
\hline \multicolumn{4}{|l|}{ Ownership of social service } \\
\hline Public & $45.2 \%$ & $48.7 \%$ & $40.3 \%$ \\
\hline Private & $54.8 \%$ & $51.3 \%$ & $59.7 \%$ \\
\hline
\end{tabular}




\subsection{Data Method}

Starting from the data collected, we aimed to identify factors associated with the quality of life among older persons, using a logistic regression model. Logistic regression is used when the dependent variable of a regression model is a binary variable and can take only two values, usually encoded with 1 , success, and 0 , failure [41]. The value 1 expresses the occurrence of a certain event and the purpose is to estimate the probability of occurrence of that event according to the values of the independent variables.

The general form of the model for a single dependent variable is:

$$
P(y=1 \mid x)=\frac{e^{\alpha+\beta x}}{1+e^{\alpha+\beta x}}
$$

The expression $P(y=1 \mid x)$ represents the probability of occurrence of the value $y=1$ conditioned by the value $x$.

The logit transformation of this probability is:

$$
\ln \left(\frac{P(y=1 \mid x)}{1-P(y=1 \mid x)}\right)=\alpha+\beta x
$$

For simplicity, let us consider $P(y=1 \mid x)=p$, according to the notation from the binomial probabilistic model, $p$ indicating the probability of success. The logit transformation is required to project the probability $p$ from the interval $(0,1)$ to the interval $(-\infty,+\infty)$, which is necessary for estimating the parameters.

In practice, the odds ratio is frequently used:

$$
O R=\frac{p}{1-p}, \text { where } \frac{p}{1-p}=e^{\alpha+\beta x}
$$

If the logistic regression model has several explanatory variables, the general form of the model becomes:

$$
\ln \left(\frac{P\left(y=1 \mid x_{1}, x_{2}, x_{3}, \ldots, x_{k}\right)}{1-P\left(y=1 \mid x_{1}, x_{2}, x_{3}, \ldots, x_{k}\right)}\right)=\beta_{0}+\beta_{1} x_{1}+\beta_{2} x_{2}+\cdots+\beta_{k} x_{k}
$$

With odds ratio:

$$
O R_{x 1, x 2, \ldots, x k}=\exp \left(\beta_{0}\right) \cdot \exp \left(\beta_{1} x_{1}\right) \cdot \ldots \cdot \exp \left(\beta_{k} x_{k}\right)
$$

Each $\beta_{i}$ expresses the contribution of the corresponding factor to the explanation of the probability of occurrence of the event $y=1$.

\subsection{Description of Variables}

In order to identify the factors influencing the quality of life, we used as a dependent variable in the logistic regression model the subjective perception of the respondents regarding the meaning of life. The constructed binary variable takes the value 1 if the respondent considers that "My life makes sense, and those around me help me a lot". The variants: "My life has lost its meaning, but those around me help me a lot" and "My life has lost its meaning, and those around me do not help me much" have been coded with the value 0 , considering that people who no longer see the meaning of their lives have a low quality of life.

As explanatory variables, we took into account some socio-demographic characteristics, but also other variables were considered important in determining the quality of life, the information being obtained from specific questions included in the questionnaire.

Gender is a binary variable that takes the value 1 in the case of a male respondent. To quantify the age of the respondents, we used a categorical variable with the values: 1 for the age group 65-74 years, 2 for the range 75-84, and 3 for the respondents who are 85 years or older. The residence is also an alternative variable, where 1 represents the urban residence 
and 0 the rural residence. Marital status was included in the analysis with the value 1 for people who have a partner (married or consensual union/cohabitation) and 0 for single people (unmarried, divorced or widowed). The level of education of the respondent refers to the last school graduated, being a categorical variable with three possible variants: 1 for ISCED 0-2, 2 for ISCED 3-4 and 3 for ISCED 5-8. The income is expressed in hundreds of RON (Romanian currency, RON $100=$ EUR 20.52), being a continuous numerical variable.

To quantify the impact of social services on quality of life, we included, as explanatory factors: a variable that quantifies how long the respondent received social services, service time, a continuous numerical variable expressed in years; an alternative variable, accommodation, indicating whether or not the respondent benefits from social services with accommodation.

The subjective assessment of well-being was included in the analysis through a binary variable (health) that takes the value 1 if the respondent is in good health and the value 0 if the respondent declared that his health is not exactly good, or it gets worse as time goes on-this affecting his life.

The functional autonomy of the respondents was evaluated based on two binary variables: (i) dependency, which takes the value 1 if the respondent needs other people's help in everything he does, respectively, 0 if the respondent manages alone sometimes or manages alone in most situations; (ii) walking difficulties, an alternative variable with the value 1 if the person chose one of the answers: "I can only walk with the help of another person", "I can only walk with the help of a support device" or "I can't walk at all"; the value 0 was assigned to the situation in which the respondent can easily walk alone.

The food and nutrition indicators focused both on qualitative and quantitative aspects: we constructed two binary variables for which the value 1 indicates adequate quantitative/nutritional food always available versus the value 0 which indicates that the respondent's diet is not always satisfactory.

As the study aims to analyze the beneficiaries of social services, we considered it appropriate to introduce a variable to indicate the safety felt by respondents during the services they receive and how this influences their quality of life. The binary variable takes the value 1 if the respondent declares that he is well cared for and does not worry about safety and 0 if he worries about his safety.

The importance of friends and loved ones for quality of life was quantified using the loneliness variable which takes the value 1 if the respondent said he feels he has no one around, he is alone, and the value 0 if the respondent has close people who help him not feel alone.

The last dimension included in the analysis refers to the living environment (home and community) of the elderly people who benefit from social assistance. Two binary variables were constructed to describe whether respondents carry out activities outside the home/residential center and whether they are satisfied with the recreation facilities available in the area where they live.

\section{Results and Discussions}

We started the analysis by investigating the explanatory variables related to quality of life. For this, we used Cramer's V Coefficient, which measures the association between two binary variables. The results indicated a moderate or strong association between diet quality and food quantity (0.63), walking difficulties and dependency (0.57) and walking difficulties and outside activities (0.44). Consequently, we decided to eliminate from the econometric analysis the variables walking difficulties and food quantity.

The results of the logistic regression are presented in Table 3.

The results show that, among the variables included in the analysis, the gender of the respondents influences the quality of life-men being more prone to consider that life does not make sense, compared to dependent elderly women. People aged 85 years and over are more likely to think that life makes sense, compared to people aged 65-74, and a higher income is associated with a higher probability of considering that life does not 
make sense. This result can be explained by the fact that people with a high level of income do not have material deficiencies that make their life difficult and are more concerned with the qualitative aspects of life. The duration of time since the respondent receives social service is statistically significant and has a positive influence on the perception that life makes sense. From this point of view, the results indicate a positive influence of the social services on the lives of the elderly.

Table 3. The results of the logistic regression.

\begin{tabular}{|c|c|c|c|c|}
\hline \multicolumn{2}{|c|}{ The Perception That Life Has Meaning ${ }^{a}$} & B & $\operatorname{Exp}(\mathrm{B})$ & Wald \\
\hline \multicolumn{2}{|c|}{ Intercept } & 0.266 & 1.305 & 0.100 \\
\hline \multicolumn{2}{|c|}{ Gender } & $-0.347^{*}$ & 0.707 & 2.813 \\
\hline \multicolumn{2}{|c|}{ Marital status } & 0.194 & 1.214 & 0.413 \\
\hline \multicolumn{2}{|c|}{ Residence } & -0.128 & 0.880 & 0.372 \\
\hline \multirow{3}{*}{ Education } & ISCED $0-2$ & $0^{b}$ & & \\
\hline & ISCED 3-4 & 0.013 & 1.014 & 0.003 \\
\hline & ISCED 5-8 & -0.127 & 0.880 & 0.113 \\
\hline \multirow{3}{*}{ Age } & $65-74$ years & $0^{b}$ & & \\
\hline & 75-84 years & -0.179 & 0.836 & 0.656 \\
\hline & 85 years and over & $0.439 *$ & 1.581 & 2.790 \\
\hline \multicolumn{2}{|l|}{ Income } & $-0.022 *$ & 0.978 & 2.950 \\
\hline \multicolumn{2}{|l|}{ Accommodation } & -0.052 & 1.054 & 0.053 \\
\hline \multicolumn{2}{|l|}{ Service time } & $0.052 *$ & 1.054 & 3.439 \\
\hline \multicolumn{2}{|l|}{ Health } & $1.399 * *$ & 4.052 & 35.21 \\
\hline \multicolumn{2}{|l|}{ Dependency } & $-0.690^{* *}$ & 0.502 & 10.13 \\
\hline \multicolumn{2}{|l|}{ Diet quality } & $0.461 * *$ & 1.586 & 3.873 \\
\hline \multicolumn{2}{|l|}{ Safety } & 0.166 & 1.181 & 0.052 \\
\hline \multicolumn{2}{|l|}{ Loneliness } & $-1.454^{* *}$ & 0.234 & 9.795 \\
\hline \multicolumn{2}{|l|}{ Outside activities } & 0.161 & 1.174 & 0.499 \\
\hline \multicolumn{2}{|l|}{ Recreation facilities } & -0.189 & 0.828 & 0.375 \\
\hline
\end{tabular}

a The reference category is: Life has no meaning. ${ }^{b}$ This parameter is zero because it represents the reference category. The significance level is marked in the table as follows: ${ }^{*}$ for $\alpha=0.1$ and ${ }^{* *}$ for $\alpha=0.05$. Source: Authors calculations using IBM SPSS Statistics 20.

The health status proved to be a very important factor in influencing the perception regarding the quality of life. Respondents who stated that they were in good health were four times more likely to think that life had meaning, compared to those who said that their health was not very good. In the same time, people who feel dependent on other people in various activities are more likely to consider that life does not make sense.

Proper nutrition has a positive impact on quality of life, as people who stated that their food quality is in accordance with the recommended diet are 1.6 times more likely to have a positive perception of the meaning of life. Last but not least, social participation has proven to be an important explanatory factor for the quality of life of the elderly. People who feel alone, those who feel they have no one around them, are more likely to feel that life is meaningless compared to those who have the support of those close to them. Social isolation reflects the availability and frequency of contacts with family, friends, neighbors, and community.

Among the variables proposed as influencing factors of the perception that life has meaning, considered in a broad sense an understanding of quality of life, after estimating the logistic regression model, it was observed that some of them are not statistically 
significant: marital status, level of education, type of service (with or without accommodation), the safety felt by respondents when cared for, participation in outdoor activities or satisfaction with access to recreation areas.

The regression results partially confirm the results presented in other international studies [42] regarding the elderly in general, respectively, the fact that the quality of life of the elderly worsens, especially in relation to health, autonomy, type and the frequency of social activities carried out. Different results were obtained in studies conducted by [33] on the existence of a direct correlation between old age and a negative perception of quality of life. Some authors [42] identified a positive relationship between age and the field of sensory abilities and a negative relationship with the field of social participation and intimacy.

Opinions have been expressed in theoretical and empirical studies in the field of social exclusion according to which people suffering from economic difficulties adapt their needs to the economic resources [32,43]. In this way, they become satisfied with their daily standard of living, despite the fact that they face economic difficulties. There have also been studies that reach different conclusions regarding the influence of income on the perceived quality of life. Thus, in a study conducted in 2016, based on the WHO tool, it resulted that income does not exert any influence in this area. The authors explained the results based on the social network (e.g., members of family that could have taken over from the financial burden) to which the study participants had access [33].

Socio-economic status and income have played a significant role in the quality of life of individuals [44]. The lack of a life partner had a negative influence on the perception of quality of life in the study conducted by [32]. In the present research, marital status was not statistically significant in terms of influence on quality of life, although other studies correlated the partner's lack with a higher degree of isolation of the elderly. However, even in the study conducted on dependent elderly people in our country, loneliness was a factor with a significant influence on the perception of life, without this necessarily being related to the existence/non-existence of a life partner, but rather to the lack of access to a strong social network-family, children, friends, etc.

Health status has a significant influence on quality of life from the perspective of maintaining autonomy in carrying out various activities of daily living, similarly to other studies [45]. Social services provided in residential centers or at home involve interaction between people, including aspects related not only to care, but to life in general. From a psychological point of view, it is important for the beneficiaries to feel safe, respected, valued, to have the feeling that they can make their own choices and decisions.

Regarding the factors associated with the quality of life of dependent elderly people, we can conclude that the differences between the results obtained in this study and other studies are determined mainly by the national context in which the research was conducted and the response collection tool that operationalizes different dimensions of quality of life. Second, the present study captures the perceptions of dependent elderly people at a certain point in time and not their evolution over time.

\section{Conclusions}

This research study aimed to identify factors associated with the quality of life from the perspective of older persons. This study contributes to the general understanding of determinants of QoL from the perception of older persons. The sample of the older population investigated included all older age groups of beneficiaries of social services and, thus, we appreciate that our findings cover a significant range of factors of what QoL means for older persons from Romania, being fairly consistent to other international studies. The results could be used by policy makers in the process of social policy design.

The analysis focused on the subjective component of QoL, so we chose, as proxy for the quality of life, the subjective and general assessment of respondents regarding the meaning of life. Most explanatory factors were also subjective appreciations, focusing on various aspects that can influence the quality of life of the elderly in Romania. Therefore, 
one of our study's limitations is that it cannot be seen as an exhaustive analysis of the quality of life, but more as an investigation of the subjective perceptions of the elderly regarding this subject.

Our classification of QoL explanatory variables is the result of literature review and empirical research inputs from older beneficiaries, social services providers and organizations that represent the interests of older persons. We appreciate that the dimensions of the quality of life in the national context should consider the cultural specifics and the characteristics of the social assistance system, and this is another limitation of our research.

In our study, information on the quality of life was provided by elderly beneficiaries of long-term care services from Romania.

Despite this methodological limitation, the results show that there is a series of important predictors associated with high values of quality of life among Romanian elderly persons - the health status of the elderly having a high importance in this process. Poor health status of the elderly is associated with a negative perception of quality of life of this group of people. However, the duration of time since the respondent receives social services has a positive influence on the perception that life makes sense, and this may guide social services providers to focus their policies to what is important and meaningful for elderly.

The quality of life in old age is a relevant aspect of social policy and the results indicate the need for government programs and strategies to promote improvements in social and health services and actions to disease prevention in order to improve the quality of life of dependent elderly people. Public policy measures to promote the active and dignified social participation of elderly people in society, but also to increase the degree of independence for people with long-term care needs should rely on data and information collected from beneficiaries of social services. In this line, the results support the policy makers by providing the necessary data and information to assess the performance of social and socio-medical services and to substantiate the strategies in the field of active ageing and social protection of the elderly. The findings of our study may also be used as a starting point by researchers interested in developing new QoL measures for older persons in Romania, considering the scarcity of similar studies at national level.

Author Contributions: The authors confirm contribution to the paper as follows: conceptualization, M.G., A.M., L.M.-M., E.-S.B.; methodology, M.G., A.M., L.M.-M., M.D.V.; data curation, A.M., M.D.V.; writing-original draft preparation, M.G., A.M., L.M.-M., M.D.V., E.-S.B.; writing-review and editing, M.G., A.M., L.M.-M., M.D.V., E.-S.B. All authors have read and agreed to the published version of the manuscript.

Funding: This research has been elaborated within the project "Calitatea vietii persoanelor vârstnice dependente în România", project funded by the Ministry of Labour and Social Protection, grant number 3676/28.09.2018.

Institutional Review Board Statement: Not applicable.

Informed Consent Statement: Informed consent was obtained from all subjects involved in this perception study.

Data Availability Statement: Not applicable.

Conflicts of Interest: The authors declare no conflict of interest.

\section{References}

1. Hyland, J.; Wares, J.; Beck, S.; Conacher, A. Scottish (Managed) Sustainable Health Network (SmaSH) Report, What Is the Sustainability of Models of Care for Older People? Available online: https://www.scotphn.net/wp-content/uploads/2015/10/ SMaSH-Report-What-is-the-sustainability-of-models-of-care-for-older-people-March-2013.pdf (accessed on 25 January 2021).

2. Purvis, B.; Mao, Y.; Robinson, D. Three pillars of sustainability: In search of conceptual origins. Sustain. Sci. 2019, 14, 681-695. [CrossRef]

3. Grazuleviciute-Vileniske, I.; Seduikyte, L.; Teixeira-Gomes, A.; Mendes, A.; Borodinecs, A.; Buzinskaite, D. Aging, Living Environment, and Sustainability: What Should be Taken into Account? Sustainability 2020, 12, 1853. [CrossRef] 
4. Lin, P.J.; Shiue, Y.C.; Tzeng, G.H.; Huang, S.L. Developing a Sustainable Long-Term Ageing Health Care System Using the DANP-mV Model: Empirical Case of Taiwan. Int. J. Environ. Res. Public Health 2019, 16, 1349. [CrossRef]

5. Lipszyc, B.; Sail, E.; Xavier, A. Economic Papers 469. Long-Term Care: Need, Use and Expenditure in the EU-27. Available online: https:/ / ec.europa.eu/economy_finance/publications/economic_paper/2012/pdf/ecp469_en.pdf (accessed on 25 January 2021).

6. Gorgiev, G. Sustainable Environment for Elderly People. J. Econ. Dev. Environ. People 2020, 9, 17-26. [CrossRef]

7. Center for International Research on Care, Labour \& Equalities. Sustainable Care Paper 1. Available online: http:/ / circle.group. shef.ac.uk/wp-content/uploads/2019/12/WPO_final-v2.pdf (accessed on 24 January 2021).

8. NIS. Tempo Online. Available online: http:/ / statistici.insse.ro:8077/tempo-online/ (accessed on 25 October 2020).

9. Ghenta, M.; Matei, A.; Mladen, L.; Sanduleasa, B. Qualind. In National Report within MOPACT Project; 2014; (not for public release).

10. CNVP. Protecția Socială a Persoanelor Vârstnice și Drepturile Acestora. Available online: http://cnpv.ro/wp-content/uploads/ 2020/03/Protectia_sociala_a_persoanelor_varstnice_si_drepturile_acestora.pdf (accessed on 25 October 2020).

11. Muntean, A.; Sagebiel, J. Practici în Asistenţa Socială România şi Germania, 1st ed.; Editura Polirom: Iaşi, Romania, $2007 ;$ p. 69.

12. CNPV. Asistența Socială a Persoanelor Vârstnice. Available online: http:// cnpv.ro/wp-content/uploads/2020/03/studiu-asistsoc-MP.pdf (accessed on 25 November 2020).

13. Schenk, L.; Meyer, R.; Behr, A.; Kuhlmey, A.; Holzhausen, M. Quality of life in nursing homes: Results of a qualitative resident survey. Qual. Life Res. 2013, 22, 2929-2938. [CrossRef]

14. Teofilou, P. Quality of Life: Definition and Measurement. Eur. J. Psychol. 2013, 9, 150-162. [CrossRef]

15. Carr, A.J.; Higginson, I.J. Are quality of life measures patient centred? BMJ 2001, 322, 1357-1360. [CrossRef]

16. Singh, S.; Afroz, N. Psycho-social challenges of elderly. Indian J. Posit. Psychol. 2018, 9, 173-177. [CrossRef]

17. HPM. Measures, Indicators, and Improvement of Quality of Life in Nursing Homes: Final Report. Available online: http: //www.hpm.umn.edu/ltcresourcecenter/research/QOL/Final_Report_to_CMS_Volume_1.pdf (accessed on 25 November 2020).

18. Castro-Monteiro, E.; Alhayek-Aí, M.; Diaz-Redondo, A.; Ayala, A.; Rodriguez-Blazquez, C.; Rojo-Perez, F.; Martinez-Martin, P.; Forjaz, M.J. Quality of life of institutionalized older adults by dementia severity. Int. Psychogeriatr. 2016, 28, 83-92. [CrossRef]

19. Marques, E.M.B.G.; Sánchez, C.S.; Vicario, B.P. Perception of the quality of life of a group of older people. Rev. De Enferm. Ref. 2014, 73-81. [CrossRef]

20. Carr, A.J.; Gibson, B.; Robinson, P.G. Is quality of life determined by expectations or experience? BMJ 2001, 322, 1240-1243. [CrossRef]

21. Walker, A. A European perspective on quality of life in old age. Eur. J. Ageing 2005, 2, 2-12. [CrossRef]

22. Eurostat. Available online: https://ec.europa.eu/eurostat/statistics-explained/index.php/Quality_of_life_indicators (accessed on 25 October 2020).

23. World Health Organization. Current and Future Long-Term Care Needs. Available online: http://www.who.int/chp/ knowledge/publications/ltc_needs.pdf (accessed on 25 October 2020).

24. Hall, S.; Opio, D.; Dodd, R.H.; Higginson, I.J. Assessing quality-of-life in older people in care homes. Age Ageing 2011, 40, 507-512. [CrossRef]

25. van Leeuwen, K.M.; van Loon, M.S.; van Nes, F.A.; Bosmans, J.E.; de Vet, H.C.W.; Ket, J.C.F.; Widdershoven, G.A.M.; Ostelo, R.W.J.G. What does quality of life mean to older adults? A thematic synthesis. PLoS ONE 2019, 14, e0213263. [CrossRef]

26. Bond, J. Quality of life for people with dementia: Approaches to the challenge of measurement. Ageing Soc. 1999, 19, 561-579. [CrossRef]

27. Orley, J.; Saxena, S.; Herrman, H. Quality of life and mental illness. Reflections from the perspective of the WHOQOL. Br. J. Psychiatry 1998, 172, 291-293. [CrossRef]

28. Netuveli, G.; Blane, D. Quality of life in older ages. Br. Med. Bull. 2008, 85, 113-126. [CrossRef]

29. Milte, C.M.; Walker, R.; Luszcz, M.A.; Lancsar, E.; Kaambwa, B.; Ratcliffe, J. How important is health status in defining quality of life for older people? An exploratory study of the views of older South Australians. Appl. Health Econ. Health Policy 2014, 12, 73-84. [CrossRef]

30. Walker, A. (Ed.) Quality of Life in old age in Europe. In Growing Older in Europe, 1st ed.; Open University Press: Berkshire, UK, 2005; pp. 1-29.

31. Nazroo, J.; Bajekal, M.; Blane, D.; Grewal, I. Ethnic inequalities. In Growing Older: Quality of Life in Old Age, 1st ed.; Walker, A., Hennessy, H.C., Eds.; Open University Press: Berkshire, UK, 2004; pp. 35-59.

32. Scharf, T.; Phillipson, C.; Smith, A.E. Poverty and social exclusion: Growing older in deprived urban neighbourhoods. In Growing Older: Quality of Life in Old Age, 1st ed.; Walker, A., Hennessy, H.C., Eds.; Open University Press: Berkshire, UK, $2004 ;$ pp. 81-106.

33. Soósová, M.S. Determinants of quality of life in elderly. Cent. Eur. J. Nurs. Midw. 2016, 7, 484-493. [CrossRef]

34. Hrast, M.F.; Hlebec, V.; Rakar, T. Sustainable Care in a Familialist Regime: Coping with Elderly Care in Slovenia. Sustainability 2020, 12, 8498. [CrossRef]

35. Zhou, Y.; Yuan, Q.; Yang, C. Transport for the Elderly: Activity Patterns, Mode Choices, and Spatiotemporal Constraints. Sustainability 2020, 12, 10024. [CrossRef]

36. Tester, S.; Hubbard, G.; Downs, M.; MacDonald, C.; Murphy, J. Frailty and institutional life. In Growing Older: Quality of Life in Old Age, 1st ed.; Walker, A., Hennessy, H.C., Eds.; Open University Press: Berkshire, UK, 2004; pp. $209-224$. 
37. Bornet, M.A.; Truchard, E.R.; Rochat, E.; Pasquier, J.; Monod, S. Factors associated with quality of life in elderly hospitalised patients undergoing post-acute rehabilitation: A crosssectional analytical study in Switzerland. BMJ Open 2017, 7, e018600. [CrossRef]

38. Ghența, M.; Matei, A.; Mladen-Macovei, L.; Bobârnat, E.S. Calitatea Vieții Persoanelor Vârstnice Dependente în România; Editura Universitară: București, Romania, 2020; pp. 27-77.

39. Borglin, G.; Edberg, A.-K.; Hallberg, I.R. The experience of quality of life among older people. J. Aging Stud. 2005, 19, 201-220. [CrossRef]

40. Sarvimäki, A.; Stenbock-Hult, B. Quality of life in old age described as a sense of well-being, meaning and value. J. Adv. Nurs. 2000, 32, 1025-1033. [CrossRef]

41. Hayashi, F. Econometrics, 1st ed.; Princeton University Press: Princeton, NJ, USA, 2000.

42. Bilgili, N.; Arpaci, F. Quality of life in older adults in Turkey. Arch. Gerontol. Geriatr. 2014, 59, 415-421. [CrossRef]

43. Berthoud, R.; Bryan, M. Income, deprivation and poverty: A longitudinal analysis. J. Soc. Policy 2011, 40, 135-156. [CrossRef]

44. Wang, F.; Zhen, Q.; Li, K.; Wen, X. Association of socioeconomic status and health-related behavior with elderly health in China. PLoS ONE 2018, 13, e0204237. [CrossRef]

45. Chin, Y.R.; Lee, I.S.; Lee, H.Y. Effects of hypertension, diabetes, and/or cardiovascular disease on health-related quality of life in elderly Korean individuals: A population-based cross-sectional survey. Asian Nurs. Res. 2014, 8, 267-273. [CrossRef] 